\title{
Processes Controlling Arctic and Antarctic Sea Ice Predictability in the Community Earth System Model
}

\author{
Ana C. Ordoñez, Cecilia M. Bitz, And Edward Blanchard-Wrigglesworth \\ Department of Atmospheric Sciences, University of Washington, Seattle, Washington
}

(Manuscript received 31 May 2018, in final form 25 September 2018)

\begin{abstract}
Sea ice predictability is a rapidly growing area of research, with most studies focusing on the Arctic. This study offers new insights by comparing predictability between the Arctic and Antarctic sea ice anomalies, focusing on the effects of regional differences in ice thickness and ocean dynamics. Predictability in simulated regional sea ice area and volume is investigated in long control runs of an Earth system model. Sea ice area predictability in the Arctic agrees with results from other studies, with features of decaying initial persistence and reemergence because of ocean mixed layer processes and memory in thick ice. In pan-Arctic averages, sea ice volume and the area covered by thick ice are the best predictors of September area for lead times greater than 2 months. In the Antarctic, area is generally the best predictor of future area for all times of year. Predictability of area in summer differs between the hemispheres because of unique aspects of the coupling between area and volume. Generally, ice volume only adds to the predictability of summer sea ice area in the Arctic. Predictability patterns vary greatly among different regions of the Arctic but share similar seasonality among regions of the Antarctic. Interactive ocean dynamics influence anomaly reemergence differently in the Antarctic than the Arctic, both for the total and regional area. In the Antarctic, ocean dynamics generally decrease the persistence of area anomalies, reducing predictability. In the Arctic, the presence of ocean dynamics improves ice area predictability, mainly through mixed layer depth variability.
\end{abstract}

\section{Introduction}

Sea ice predictability studies have focused mainly on the Arctic or Antarctic, with few comparative studies of Arctic and Antarctic differences, especially at the regional scale. Johnson et al. (1985) is the only paper to the authors' knowledge that makes comparisons of predictability between the pan-Arctic and pan-Antarctic and among their subdivided regions, but their study relies on observational data from a short time period and considers only a limited set of sea ice predictors. Making comparisons between the poles otherwise involves compiling results from disparate studies covering different time periods, data sources, models, and geographic regions. Such comparisons reveal some differences between hemispheres. For example, correlations of anomalies in the hemispheric total sea ice area with anomalies in future months take 2-5 months to decay in the Arctic (Blanchard-Wrigglesworth et al. 2011a; Lemke et al. 1980) and 1-2 months to decay in the Antarctic (Holland et al. 2013; Lemke et al. 1980).

\footnotetext{
Corresponding author: Ana C. Ordoñez, ordonana@uw.edu
}

Differences in geography, oceanography, and the sea ice mean state lead to differences in sea ice predictability. The Antarctic was found to lose predictability much faster than the Arctic on interannual time scales in reforecasts by Du et al. (2012). Lower predictability might be expected in the Antarctic where sea ice is strongly influenced by sea ice transport and ocean and atmosphere heat exchange, as these processes are enabled by zonal shape of the coastline and proximity to strong winds and currents (Lemke et al. 1980; Johnson et al. 1985; Holland et al. 2013).

For multiple reasons, anomalies in the hemispheric total sea ice area can reemerge after decaying from an initial persistent period. Given the diversity of causes for reemergence, it is perhaps unsurprising that the nature of the reemergence in the Antarctic was found to be distinct from that of the Arctic by Holland et al. (2013). One mechanism for sea ice area reemergence involves the interaction of sea ice and the surface ocean through the memory of sea surface temperature (SST) anomalies and the covariability of SST and sea ice area. We use the term SST-linked reemergence for this effect, but it should be understood that SST persistence is 
the means of linking initial and future sea ice area anomalies.

SST-linked reemergence of ice area can depend on ocean mixed layer dynamics, where temperature anomalies are stored under the mixed layer during summer (Holland et al. 2013; Bushuk et al. 2017). The strength of the sea ice reemergence is affected by variability in the atmosphere and ocean (Bushuk and Giannakis 2015). This suggests that predictability can evolve from multiple mechanisms on multiple time scales, making it challenging to understand sea ice predictability from the short observational record. Mixed layer depths, ocean heat transport, and other aspects of ocean-sea ice coupled processes are distinct in the two hemispheres, which could lead to differences in heat storage and hence sea ice anomaly reemergence. Holland et al. (2013) found evidence for SST reemergence from the mixed layer that influences predictability of the Antarctic sea ice edge, but this reemergence only occurs in some regions, and its signal may be obscured by sea ice and SST advection.

Another type of reemergence occurs in sea ice area between consecutive melt seasons because of persistence of sea ice volume anomalies (the so-called volumelinked reemergence), first identified by BlanchardWrigglesworth et al. (2011a). Sea ice volume anomalies persist for a longer time than area anomalies do (at least a year at the local scale and possibly several years in larger domains), and the two covary during the summer but not in winter (Blanchard-Wrigglesworth et al. 2011a). This intermittent covariance of area and volume can cause reemergence of sea ice area anomalies between consecutive melt seasons.

Because the average thickness of a region within the sea ice-covered seas is highly correlated with the volume, volume and average thickness can be considered nearly equivalent predictors of sea ice area. However, neither volume nor thickness as a predictor has received much attention in the Antarctic. An exception is Holland et al. (2013), who point to low summer sea ice area predictability as an indicator that ice thickness/ volume is not an effective predictor there, likely a result of the lack of significant areas of thick, multiyear ice that could provide memory through the summer months.

The role of sea ice volume is not limited to volumelinked reemergence. Chevallier and Salas-Mélia (2012) find that in the late spring, thick-ice area in the Arctic explains more of the variance of the following September ice area than spring total area does. While sea ice thickness is not easily observed (Haas and Jochmann 2003), thickness information is another potential source of memory for sea ice area.
There are practical reasons to improve our ability to forecast sea ice quantities. The Arctic will likely become more navigable during the twenty-first century, and knowing the timing and duration of ice-free conditions can help stakeholders make decisions about shipping, hunting, and resource extraction (Lamers et al. 2016; Smith and Stephenson 2013). New routes across the central Arctic may open up to certain classes of ships, but the most popular path across the Arctic will likely remain the crossing from the North Atlantic through to the Bering Strait (Smith and Stephenson 2013). These new routes motivate a need to better understand sea ice predictability in the seas around Alaska, the coast of Russia, and the Greenland Sea.

The Antarctic is not as traveled and populated as the Arctic, but understanding sea ice predictability in this area has scientific value and could support research operations and tourism. Results generally point to Antarctic sea ice being less predictable than Arctic sea ice. The Antarctic sea ice edge location is predictable for up to 2 years depending on the location (Holland et al.2013; Zunz et al. 2015). SST-linked reemergence is active in Antarctic ice edge predictability, but volume-linked reemergence is not (Holland et al. 2013). On an interannual basis, Antarctic sea ice area is more predictable in the winter than in the summer (Zunz et al. 2015). Guemas et al. (2016) found little to no skill in forecasts of monthly Antarctic sea ice extent using models initialized in both May and November. Debate exists on the time scales of predictability of the trend in Antarctic sea ice extent, which may be potentially predictable on decadal or longer time scales (Zunz et al. 2015) or not (Yang et al. 2016). Monthly pan-Arctic sea ice area prediction on seasonal to annual time scales has received the attention of numerous studies (e.g., Blanchard-Wrigglesworth et al. 2011a; Bushuk and Giannakis 2015; Day et al. 2014), but there are few results from the Antarctic on this time scale with which to compare it.

There are multitudes of ways in which to study sea ice predictability, many of which are described in detail in Hawkins et al. (2015). Predictability can come from initial values or from boundary conditions. Initial value predictability of sea ice is relevant in the Arctic on time scales of 3-5 years or fewer, while predictability at longer time scales is driven by boundary conditions (Blanchard-Wrigglesworth et al. 2011b). Furthermore, study methods can be divided broadly by whether they consider diagnostic or prognostic predictability. Diagnostic predictability can be calculated from a single model run or observations and includes quantities such as lagged correlations of ice area or volume. Such studies can make use of existing model output. Prognostic 
predictability is found using an ensemble of model runs with slightly different initial conditions. While prognostic predictability experiments provide insight into the limits of predictability that can be obtained in a model, which cannot be fully understood through diagnostic experiments, they are more costly and more difficult to compare with other data than diagnostic predictability studies are. Diagnostic predictability studies can produce simple, preliminary information that can be followed up with more sophisticated prognostic methods.

Most of the predictability results from the Antarctic are from prognostic predictability studies (e.g., Holland et al. 2013; Zunz et al. 2015). Lemke et al. (1980) and Johnson et al. (1985) are the only examples of diagnostic monthly predictability from initial values that could be compared with Arctic studies like BlanchardWrigglesworth et al. (2011a), Bushuk and Giannakis (2015), and Day et al. (2014). As a first step toward addressing interhemispheric predictability, we use an Earth system model to investigate diagnostic sea ice predictability in a long control run. This model output provides a comprehensive and consistent source of data for these comparisons. The diagnostic approach is computationally simple and facilitates easy comparisons across regions, variables, and model configurations.

This paper is organized as follows: Section 2 details the datasets and analysis used in this study. Section 3 compares sea ice area and volume predictability in simulations with differing ocean dynamics. Sections $3 a$ and $3 \mathrm{~b}$ discuss hemispheric-wide predictability in the Arctic and Antarctic, respectively. Section 3c then describes predictability within subregions of each sea ice zone. Section $3 d$ analyzes different ice cover variables to find those that best predict September and March ice area in the Arctic and Antarctic. Section 4 contains our conclusions and directions for future work.

\section{Model simulations, methods, and evaluation of simulated sea ice climatology}

This study uses two long control simulations of Community Earth System Model, version 1 \{Community Atmosphere Model, version 5 [CESM1(CAM5)]\}, which are part of the CESM Large Ensemble (CESMLENS) project (Kay et al. 2015). The first simulation is an 1850s preindustrial control run with full-depth "dynamical" ocean general circulation model (DYN), and the second is an 1850s preindustrial run with a slabocean model (SOM). These simulations are compared to reveal whether ocean dynamics affect sea ice predictability similarly in both hemispheres. The dynamical ocean run could be expected to have greater sea ice area predictability associated with SST-area reemergence, which involves anomalous temperature and depth variations in the ocean mixed layer. The role of a dynamical ocean compared to a slab ocean in predictive models was previously investigated by Blanchard-Wrigglesworth et al. (2011a) and Bushuk and Giannakis (2015). Advection of sea ice has been shown to affect predictability differently in the Arctic and Antarctic (Holland et al. 2013; Johnson et al. 1985; Lemke et al. 1980), which provides a reason to also expect interhemispheric differences in predictability between DYN and SOM. While our analysis cannot isolate the effects of individual dynamical processes, such as advection or upwelling, it suggests processes to investigate in more detail.

In these control runs, greenhouse gas concentrations are set at 1850 s values, although carbon-nitrogen cycling is simulated in the land component. The ocean and sea ice components have a nominal $1^{\circ}$ resolution on a displaced dipole grid. The atmosphere and land components have approximately $1^{\circ}$ resolution. The ocean heat flux convergence and currents prescribed in SOM were derived from the monthly climatology of DYN. The slab depth of SOM is prescribed from the annualmean climatological mixed layer depth of DYN. The SST in SOM evolves in response to the balance of heat fluxes incident at the surface.

The run lengths are 2200 years for DYN and 1001 years for SOM. Studies have shown that Arctic sea ice has large variability at quasi-decadal to centennial time scales (Venegas and Mysak 2000; Zhang 2015), and lowfrequency variability in the ocean and atmosphere has the potential to greatly influence sea ice predictability over years and decades (Bushuk and Giannakis 2015). By analyzing output from the last 500 years of each run, we ensure that we avoid evaluating a short-term fluctuation. All analysis is with monthly mean anomalies, unless otherwise specified.

Because the climate's mean state has been found to affect sea ice predictability (Holland et al. 2011), before presenting our analysis of the predictability on hemispheric and regional scales, we discuss the agreement of the mean state in DYN and SOM and wherever possible compare with observations.

The observations we use for sea ice concentrations in Figs. 1 and 2 are from passive microwave satellites using the bootstrap algorithm for 1979-2017 (Comiso 2000). The sea ice concentration from both model and satellite are converted into a pan-Arctic extent for comparison. The extent is the sum of all area in grid cells with $15 \%$ or greater sea ice concentration, while area is the sum of the gridcell areas weighted by the sea ice concentration. Extent is used for the model-satellite comparison because satellites tend to underestimate the area when the surface is melting [Ivanova et al. (2014) and Meier et al. 


\section{(a) Arctic}
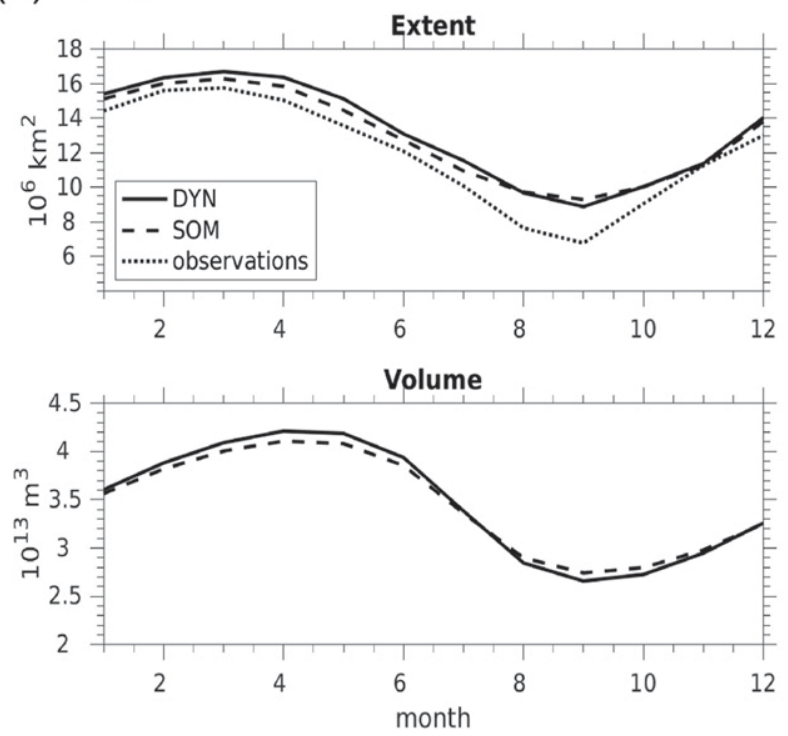

(b) Antarctic
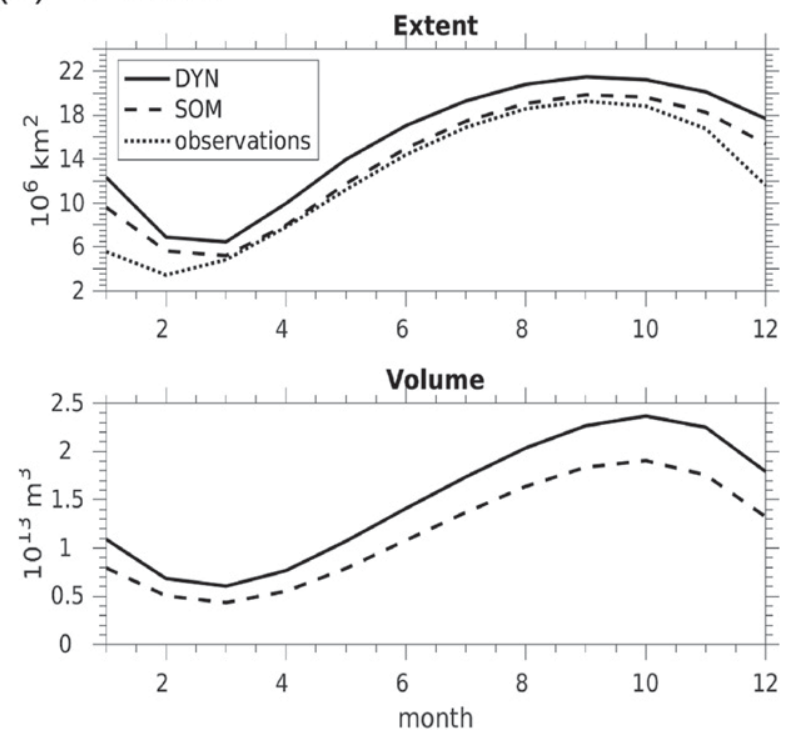

FIG. 1. Monthly climatological mean hemispheric total sea ice extent and volume in the (a) Arctic and (b) Antarctic for DYN (solid), SOM (dashed), and observations (dotted). The simulated extents in DYN and SOM are from 1850s controls and the observations are from 1979 to 2014.

(2015) discuss this and other issues with passive microwave sea ice detection]. However, there are subtle differences in the predictability of sea ice area and extent (Blanchard-Wrigglesworth et al. 2011a). Sea ice extent is slightly less predictable than area, most likely because of the effects of unpredictable wind forcing. For example, winds can cause divergence in the ice pack and spread the ice over a broader region. As long as the ice concentration remains above $15 \%$, this divergence will increase the ice extent without increasing the area. Furthermore, ice extent is an arbitrary metric based on satellite retrieval accuracy, while ice area is more physically fundamental. For these reasons, we consider total area when assessing predictability. When making comparisons between the models and observations on a regional scale in Fig. 2, the following correction is made to account for differences in the land masks between the model and observation datasets.

The model output is regridded onto the $25-\mathrm{km}$ stereo grid of the passive microwave satellites' observations, and any grid cells that contain land in either dataset are excluded from the ice extent count.

The monthly climatology of pan-Arctic sea ice extents simulated in DYN and SOM are within $0.53 \times 10^{6} \mathrm{~km}^{2}$ of one another (Fig. 1), which we consider an indication of quite reasonable success at constructing a mean state in the SOM in agreement with DYN. The simulated extents are greater than observed (Comiso 2000; Fig. 1), which is unsurprising given that the simulations are forced with preindustrial greenhouse gas forcing. In the
Arctic, the model's sea ice coverage is more extensive than the observed by as much as $2 \times 10^{6} \mathrm{~km}^{2}$. Other studies have shown that historical simulations of CESM-LENS perform well at simulating Arctic sea ice extent over recent years. Jahn et al. (2016) show good agreement between observations and CESM-LENS simulations for mean Arctic ice thickness and extent in the early twenty-first century, and Barnhart et al. (2016) show that CESM-LENS captures the trend of declining sea ice extent over the period of satellite observations.

In the Antarctic, DYN has roughly $2-3 \times 10^{6} \mathrm{~km}^{2}$ more sea ice extent year-round than SOM does, but the seasonal range of DYN and SOM match well. There is a much larger discrepancy between the Antarctic model simulations and observations, with summer extent in the DYN exceeding observations by as much as nearly $7 \times$ $10^{6} \mathrm{~km}^{2}$. This is likely due in part to the preindustrial climate of DYN, though CESM1(CAM5) still has a bias toward large sea ice extents in the Antarctic in modern-day simulations (Meehl et al. 2013). A bias in earlier versions of the model was related to wind stress (Meehl et al. 2013) and similarities in the bias between DYN and SOM also suggest a role for the atmosphere component.

In the subregions we consider in our analysis, the biases in sea ice extent in DYN and SOM are similar to each other (see Fig. 2). In the Arctic subregions, the simulated sea ice extents are usually biased by no more than $0.5 \times 10^{6} \mathrm{~km}^{2}$, as were pan-Arctic sea ice extent 
(a) Arctic

(1) Monthly mean ice extent
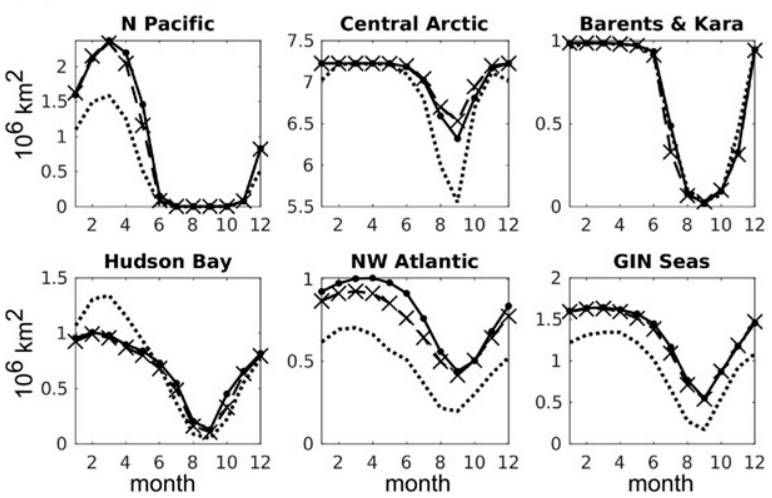

(b) Antarctic
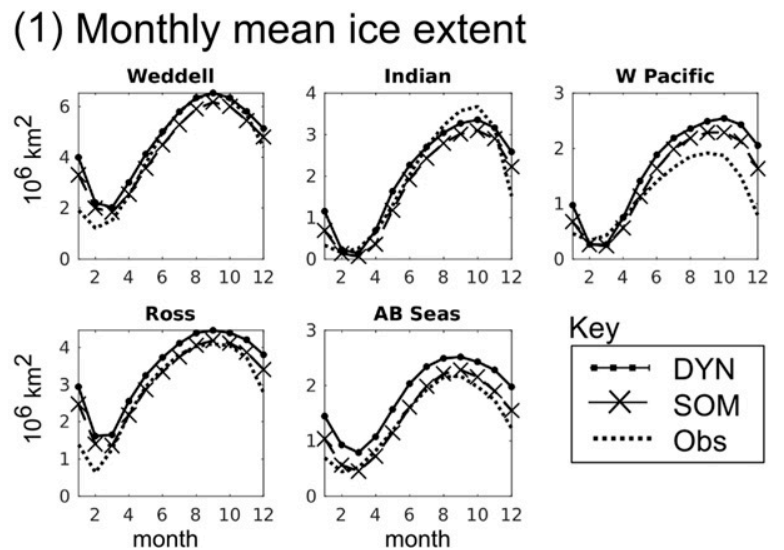

(2) Region map

Region Key:

1. North Pacific

2. Central Arctic

3. Hudson Bay

4. NW Atlantic

5. GIN Seas

6. Barents \& Kara Seas



(2) Region map

Region Key:

1. Weddell Sea

2. Indian Ocean

3. West Pacific

Ocean

4. Ross Sea

5. Amundsen \& Bellingshausen Seas

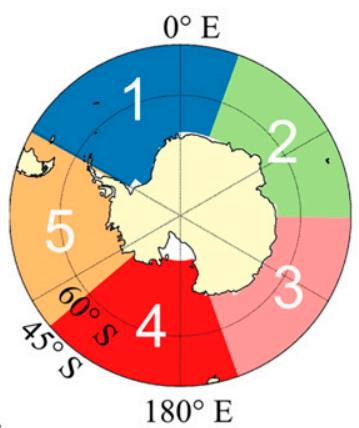

FIG. 2. As in Fig. 1, but for extent in subregions with maps showing the division of regions within each hemisphere. DYN is a solid black line, SOM is a dashed line with $\times$ symbols, and the observations are a dotted line.

biases. However, the regional biases are a far larger percentage of the subregions' extent than were the hemispheric totals. The model generally oversimulates winter Arctic sea ice extent. This bias is consistent throughout the year in the northwest Atlantic and Greenland-Iceland-Norwegian (GIN) Seas regions. In the North Pacific and Hudson Bay, the simulations are too extensive in winter. In the central Arctic, the simulations are too extensive in summer. Around the Antarctic, the sea ice zone was divided into five subregions (Fig. 2), similar to Parkinson and Cavalieri (2012). The mean annual cycles of extent are similar to one another in DYN and SOM, though DYN generally has slightly greater extent than SOM. In the Antarctic, the model is generally close to observations in the fall except in the west Pacific and Indian Oceans. The summer retreat in both simulations is delayed relative to the observations. The simulated sea ice is too extensive during the melt seasons in all subregions, especially in the Weddell and
Ross Sea regions. We suspect that biases in summer extent, which indicate too much multiyear sea ice, coincide with biases in thickness and volume in these regions.

Like sea ice extent, Arctic sea ice volume is similar in DYN and SOM, with differences of less than $0.25 \times$ $10^{13} \mathrm{~m}^{3}$. DYN and SOM agree less well in the Antarctic, where differences are around $0.5 \times 10^{13} \mathrm{~m}^{3}$ in the summer and $1 \times 10^{13} \mathrm{~m}^{3}$ in the winter. DYN, which had larger monthly mean areas than SOM in the Antarctic, also has larger monthly mean volumes.

The lack of ice thickness observations for Antarctic sea ice makes it difficult to quantify these biases for CESM. Shu et al. (2015) compare the CMIP-5 models with Global Ice-Ocean Modeling and Assimilation System (GIOMAS), a model with ice data assimilation, and find that during the historical period, CESM1(CAM5) captures the Antarctic total mean sea ice volume well, though the spatial pattern of ice thickness is less well 
represented. GIOMAS is only one of a number of reanalysis systems used to estimate present-day sea ice volume; in the Arctic, there is a great amount of spread in the ice thickness fields generated by reanalysis models (Chevallier et al. 2017), suggesting that one reanalysis alone may not be a reliable comparison for determining Antarctic ice thickness bias.

The degree to which thickness biases affect ice area predictability is uncertain. Holland et al. (2011) found that predictability of sea ice volume was reduced when the ice was initialized anomalously thin, and BlanchardWrigglesworth and Bitz (2014) found that thickness anomalies decayed more quickly in models with thinner sea ice. However, Blanchard-Wrigglesworth et al. (2011a) compared Arctic diagnostic ice area predictability between the periods 2001-30 and 2031-60 and found no appreciable differences despite changes in the mean ice conditions, while Cheng et al. (2016) found subtle changes in persistence over the twentieth and twenty-first centuries in CESM1 simulations, with an increase in persistence from early summer to fall and a decrease in persistence from winter to winter. While sea ice predictability in the Arctic and Antarctic of these preindustrial simulations may be overestimated relative to the modern climate, the results from this study are likely still relevant for understanding the processes that control predictability today.

Our analysis in section 3 uses lagged correlations of detrended predictor and predictand to quantify diagnostic predictability. A two-tailed $t$ test is used to determine significance at the $95 \%$ confidence level. Correlations are performed on both panhemispheric and regional ice area and volume.

\section{Predictability results of DYN and SOM}

In the first part of this section, we present the predictability of pan-Arctic sea ice area and volume. Next, we compare the pan-Arctic and pan-Antarctic results. This is followed by analysis of predictability on regional scales within each hemisphere. Finally, we investigate the effectiveness of variables other than area and volume for predicting area in two subregions of the Arctic.

\section{a. Hemispheric predictability}

\section{1) InItial DECAY of PREDiCTABILITy IN ARCTIC SEA ICE AREA AND VOLUME}

The lagged correlations of pan-Arctic sea ice area and volume are shown in Fig. 3a. This type of figure, used throughout sections $3 a-3 c$, is a forward-looking perspective of predictability_indicating how a given initial anomaly relates to anomalies in subsequent months. In these plots, each row is a correlation of an initial month (indicated by the row's label) with a target month in the future (indicated by the number along the horizontal). As an example, consider a row labeled July in Fig. 3a, the first column (target month 0 ) is the autocorrelation at zero lag, so it is 1 . One column to the right (target month 1) is the correlation of July and the following August. The correlations remain high through target month 5, which is the correlation of July with the following December.

Similar experiments and analyses were described in Blanchard-Wrigglesworth et al. (2011a), Bushuk and Giannakis (2015), and Day et al. (2014), and next we will compare our results to their findings. For sea ice area in Fig. 3a, the largest initial persistence (and hence greatest predictability) occurs for an initial month in JanuaryMarch and July-August in both DYN and SOM, near the seasonal maximum and minimum when the area seasonally changes the least, as discussed in BlanchardWrigglesworth et al. (2011a). Predictability is lowest for spring and fall months in both simulations. Despite the preindustrial climate forcing in these simulations, the lagged correlations of pan-Arctic area are similar to those from modeling and observations of the modern era shown in Blanchard-Wrigglesworth et al. (2011a) and Day et al. (2014). The SOM has lower predictability than DYN at all lags, in agreement with results in Blanchard-Wrigglesworth et al. (2011a) and Bushuk and Giannakis (2015).

Pan-Arctic volume is highly persistent in both simulations, though slightly more so in DYN. The persistence in our simulations is greater than has been seen in all but one model discussed by Day et al. (2014), who compared lagged monthly correlations in Arctic sea ice extent across five global climate models. A similar diagnostic analysis of volume predictability in the CESM-LENS historical runs 1-30 for years 1979-2008 (not shown) revealed that, on average, summer-to-summer persistence had correlations of $r=0.60-0.70$ versus $0.80-0.90$ in the preindustrial DYN case. This difference may be due to mean-state differences in these simulations.

\section{2) ReEMERgenCE of PREDiCTABILITY IN ARCTIC SEA ICE AREA ANOMALIES}

Signals of SST-linked and volume-linked reemergence are clearly visible in the lagged correlations of pan-Arctic sea ice area in Fig. 3a (top row) as diagonal bands of relatively high correlation extending from the zero lag. Both DYN and SOM have this pattern, and the timing is similar in both. The SST-linked reemergence links sea ice area in March with February, April with January, May with November, and June with November, as the lag time of the reemergence decreases from the spring to summer. 


\section{(a) Pan-Arctic lag correlations}
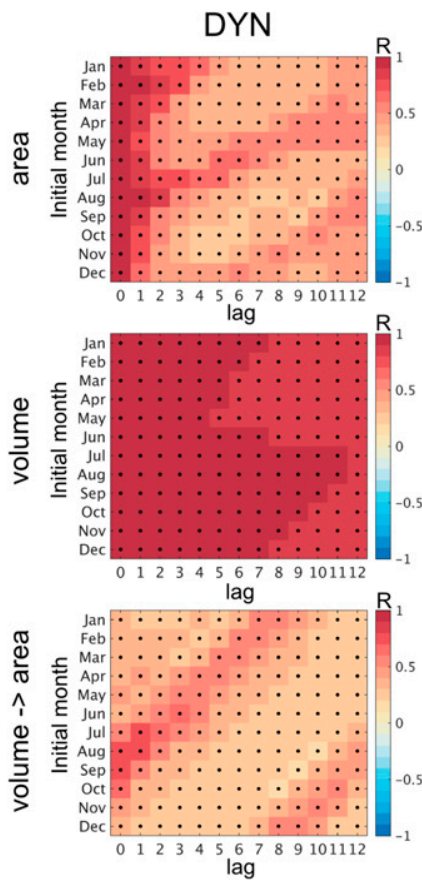

(b) Pan-Antarctic lag correlations
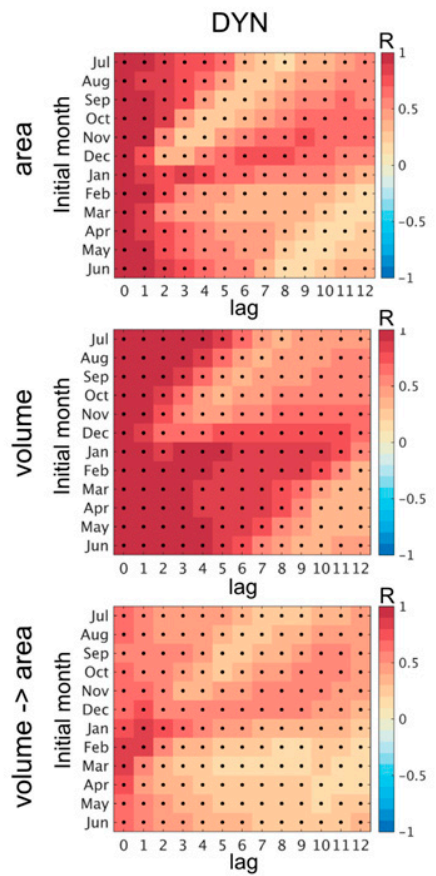
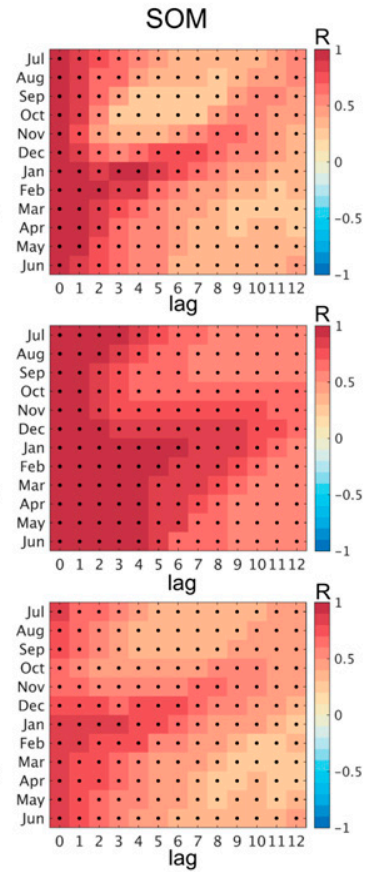

FIG. 3. Lagged correlations of area with area, volume with volume, and volume with future area for the (a) pan-Arctic and (b) panAntarctic in the DYN and SOM simulations. Antarctic plots are offset by 6 months relative to Arctic plots. Significant correlations are marked with a black dot.

The volume-linked reemergence, also seen in the areaarea correlations, links sea ice area in the months of September with September, October with August, November with July, and December with June. The timing and strength of reemergence in DYN especially are similar to results from Blanchard-Wrigglesworth et al. (2011a) and Day et al. (2014).

Generally, the reemergence signals of sea ice area are weaker in SOM than in DYN, in agreement with results from Blanchard-Wrigglesworth et al. (2011a) and Bushuk and Giannakis (2015). This difference between SOM and DYN has parallels with a study of SST reemergence by Alexander et al. (2000). They investigated winter SST lagged correlations for a variety of mixed layer conditions in three different data sources-a coupled mixed layer model, a simple stochastic model with fixed mixed layer depths, and observations. Alexander et al. (2000) found SST reemergence in the North Atlantic between winters in both the coupled model and in observations (see their Fig. 13), while the stochastic model with fixed mixed layer depths experienced no SST reemergence, just exponential decay of SST anomalies in time. This comparison shows that fixed mixed layer depths, even with a seasonal cycle, are inadequate to support the mixed layer processes that lead to SST reemergence. In our study, DYN has dynamic mixed layer depths similar to Alexander et al.'s coupled model, while SOM has fixed mixed layer depths like their stochastic model. In Fig. 3a, ice area correlations remain significant between periods of reemergence in DYN. In SOM, correlations decay to nearly zero after the period of initial persistence and are lower than DYN during periods of reemergence. The results in Alexander et al. (2000) suggest that differences in the mixed layer depths of the DYN and SOM on SST are a leading cause of differences in sea ice predictability from SST-linked reemergence in the Arctic. Unfortunately, SST output was not saved from SOM, so it is not possible to compare SST correlations in SOM and DYN.

Coupled interactions of ocean heat flux convergence (horizontal or vertical) and the location of the sea ice edge has been proposed as a mechanism to provide persistence between sea ice area in subsequent winters (Holland et al. 2011), and if this were the case, the absence of coupling in the SOM would explain the weaker SST-linked reemergence. While winter-to-winter correlations are lower in SOM than in DYN, they are not eliminated. It appears that the ocean heat flux convergence is not the only source of sea ice area persistence between winters; based on the volume-area plots, it 
appears that basic persistence of mixed layer temperature is also an important player.

\section{3) Predicting SeA ice AReA From volume}

We take a closer look at the volume-area relationship and its role in reemergence by computing correlations between initial volume and target month area (Fig. 3a, last row; denoted volume $\rightarrow$ area in the figure). Our volume-area results expand on those in BlanchardWrigglesworth et al. (2011a), who showed that thickness in summer could be used to predict September concentration near the ice edge because of their high correlation. In the last row of Fig. 3a, we see a banded pattern in which volume is positively correlated in all months with the upcoming summer area, which shows that knowing volume/thickness offers the highest potential predictability for forecasting area in summer. Further, we see that the high-correlation bands align only in the latter half of the year (i.e., following initial months of July-December) for the area-area and volume-area lagged correlations in Fig. 3a. Where these bands align, we interpret the area reemergence is driven by persistence in volume. In fact, the band of high correlation in the upper half of the area-area plot aligns with a minimum in the volume-area correlation, reinforcing the prevailing view that this band in the areaarea plot is driven by something other than volume persistence (rather that area predictability during the fall is from SST persistence). The implication is that a forecast of summer sea ice area can be made roughly equally well by knowing sea ice volume the prior winter/ early spring or by knowing either volume or area the prior summer/fall. Further, we surmise that a forecast system initialized with sea ice thickness anomalies can make skillful summer forecasts earlier in spring than one that is only initialized with sea ice area anomalies and a climatological estimate of thickness. However, as pointed out in Day et al. (2014), the lack of sea ice thickness observations has limited the practicality of thickness/volume as a predictor of summer ice area. Indeed the lack of thickness observations may explain why some studies have shown that forecast skill increases with lead time if the lead time stretches into a period with area reemergence (e.g., Sigmond et al. 2013; Msadek et al. 2014). In section 3d we explore September area predictability from volume in greater detail and consider other variables that could be good predictors.

\section{4) Comparing PRedictability in the ARCTiC AND ANTARCTIC}

In striking contrast to the Arctic, sea ice predictability of pan-Antarctic area and volume are similar in DYN and SOM (Fig. 3b), indicating that ocean dynamics has little influence on pan-Antarctic sea ice predictability. Initial persistence of area in Antarctic DYN and SOM is similar to that in Arctic DYN, with the longest initial persistence in winter (June-August) and summer (January and February) months. Both Antarctic DYN and SOM have greater persistence of area following the spring months than was found in the Arctic.

There is nearly equally strong SST-linked reemergence in the Antarctic in DYN and SOM (Fig. 3b). Holland et al. (2013) discuss the possible effects of ocean dynamics on SST-linked reemergence on Antarctic sea ice due to mixed layer deepening and shoaling. They were able to show that SST-linked reemergence from the mixed layer occurred in their model, though they did not perform a control experiment without ocean dynamics to isolate the effect of dynamics on the sea ice predictability. Our results suggest that a variable mixed layer depth is actually less important for sea ice area predictability than basic mixed layer temperature persistence.

Neither DYN nor SOM shows sea ice volume-linked reemergence in the Antarctic in Fig. 3, which is a major departure from the Arctic results. Holland et al. (2013) also noted a lack of volume-linked reemergence in their results. Because of long persistence of the initial area anomalies after the growth season in the Antarctic, there is still some area predictability in the following spring, but not from volume-linked reemergence like in the Arctic.

Volume-volume correlations are highly persistent in the Antarctic until the summer months, when they decay quickly. While in the Arctic, DYN has as much or more sea ice volume predictability than SOM, in the Antarctic, DYN generally has lower sea ice volume predictability, particularly at long lags. DYN loses predictability quickly over target months in the summer relative to SOM. This difference between SOM and DYN suggests that Antarctic ice area prediction systems that do not include the effects of ocean dynamics will be overconfident in forecasts based on volume, particularly for forecasts targeting the summer season. It appears that there is inherently less memory in ice volume in the Antarctic than in the Arctic, consistent with the fact that Antarctica has lower ice volume to area ratios (and hence generally lower thickness) in both simulations (Fig. 1).

The patterns of lagged volume-area correlation (Fig. 3, bottom row) have large differences between the two hemispheres. Unlike in the Arctic, the pattern of Antarctic volume-area correlations resembles areaarea correlations. SOM has slightly larger volume-area correlations than DYN, also in contrast with the Arctic. These volume-area correlations do not exceed those of area-area correlations in either DYN or SOM, suggesting that volume is generally no better than area as a diagnostic predictor of future area. 
The lack of volume-linked reemergence in the Antarctic and the differences in volume $\rightarrow$ area correlations indicate that volume plays a different role in Arctic and Antarctic sea ice area predictability. In the Arctic, coupling between area and volume in the summer improves summer area predictability, while it does not in the Antarctic. With much thinner sea ice than in the Arctic, Antarctic sea ice volume should have less persistence and vary on shorter time scales (Bitz et al. 1996). Therefore, it is perhaps no surprise that there is less differentiation between the persistence of area and volume anomalies in the Antarctic, as can be seen in Fig. 3b the first row of Fig. $3 b$ versus the middle row of Fig. $3 b$.

\section{b. Regional predictability in the Arctic}

This section describes sea ice area predictability on a regional scale in the Arctic. Many authors have already investigated regional sea ice predictability, though only Bushuk and Giannakis (2015) also compared the influence of slab-ocean and dynamical ocean components at the regional scale. Day et al. (2014), Bushuk et al. (2017), and Bushuk et al. (2018) used a prognostic predictability framework in their analysis of regional Arctic sea ice area and volume predictability. Bushuk et al. (2015) performed a diagnostic analysis of monthly lagged correlations of spatial patterns in the Arctic from a long control run of CCSM3.

The Northern Hemisphere sea ice zone was divided into six nonoverlapping regions (Fig. 2b). Neighboring marginal seas were grouped together to simplify this analysis in a manner similar to that in Cavalieri and Parkinson (2012). The regional sea ice extents in the model and in observations differ as discussed in section 2 for the Arctic. Only the area-area predictability is presented in Fig. 4, similar to Fig. 3 (top row).

The diversity of patterns in Fig. 4 shows that sea ice area predictability can vary dramatically by region, but generalizations can be made. As found in the pan-Arctic results, the longest persistence in each subregion follows initial months in the winter and summer (e.g., January and July, with specific months varying by region). The central Arctic area is an exception where variability in the winter is negligible. This persistence trait is also seen in sea ice regional variability in CCSM3 by Bushuk et al. (2015) and in CCSM4 by Bushuk and Giannakis (2015).

The predictability of sea ice area is broadly similar in DYN and SOM for each region, though it is weaker in SOM in all regions other than the central Arctic and Hudson Bay, two areas that are mostly isolated from significant ocean dynamics. While we identify the BarentsKara and GIN Seas as having the greatest predictability, Day et al. (2014) identified the Labrador Sea as having predictability for the longest period. The Labrador Sea that Day et al. (2014) defined overlaps with our northwest Atlantic region, but the latter region does not have especially large predictability in Fig. 4. It may be that low predictability in the northern Baffin Bay is reducing the mean predictability of the northwest Atlantic, or our model may have unusually weak iceocean coupling in the Labrador Sea compared to the models studied by Day et al. (2014).

Most regions have SST-linked reemergence, but the amount differs greatly by region. The largest SST-linked reemergence is in the Barents-Kara and GIN Seas, which are also regions with deep and variable mixed layers and high ocean heat flux convergence in CESM. It is perhaps no surprise that these are also regions where SST-linked reemergence in the SOM falls most short compared to DYN. Bushuk and Giannakis (2015) also observed in their study that SST-linked reemergence was generally weaker in an integration with a slab-ocean compared to a dynamical ocean component.

Predictability of ice area between winters is found in all regions except the central Arctic and Hudson Bay (Fig. 4). This predictability is present in both runs but is slightly stronger in DYN than in SOM. These results suggest that interactive ocean dynamics contribute to predictability between winters on a regional scale as discussed in the pan-Arctic results in section 3a(1) and in Holland et al. (2011).

Volume-linked reemergence (e.g., summer-summer) is most apparent in the central Arctic, while in most other regions, the initial persistence is competitive with reemergence as a source of predictability. In the GIN Seas especially, sea ice advection may be interfering with volume-linked reemergence. Ice thickness anomalies are short lived in the GIN Seas region (BlanchardWrigglesworth and Bitz 2014), making it unlikely that reemergence is due to the sea ice itself. Area predictability in June-September is generally low in all regions when initialized more than a couple months in advance, but it is higher in CESM than in the model used in Bushuk et al. (2015, 2018).

We have noted that regional predictability is considerably weaker in SOM than in DYN. Fortunately, the mean state in the Arctic is so similar between SOM and DYN that we can rule out mean-state effects on the predictability. We thus conclude that ocean dynamics are important for predicting Arctic sea ice, especially for forecasts initialized in winter.

\section{c. Regional predictability in the Antarctic}

One of the most remarkable aspects of the lagged correlation of Antarctic sea ice area by subregion in Fig. 5 is the similarity of the patterns across regions compared to the inconsistencies among patterns in the 
(a) DYN area correlations

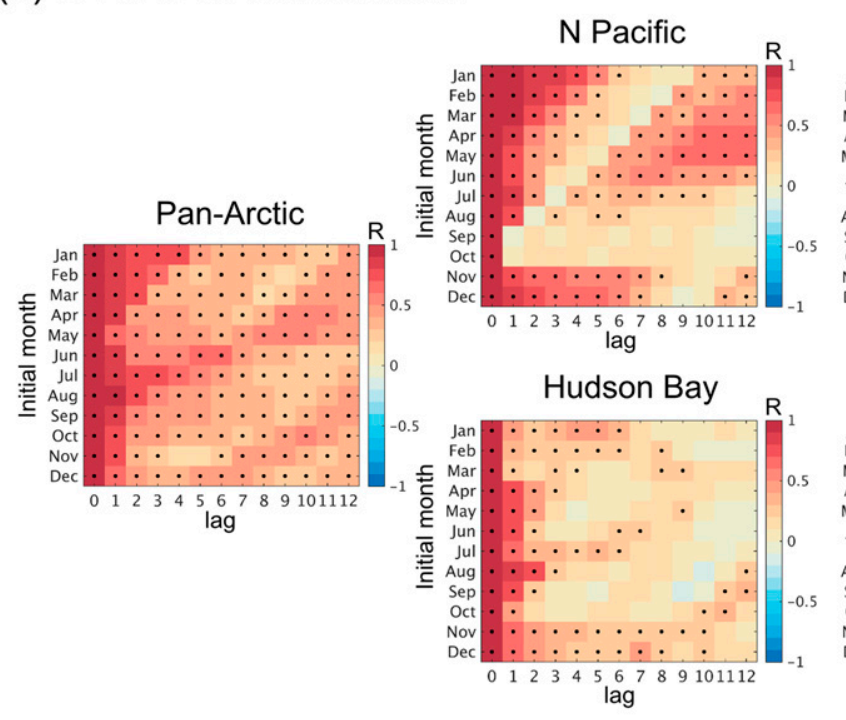

(b) SOM area correlations

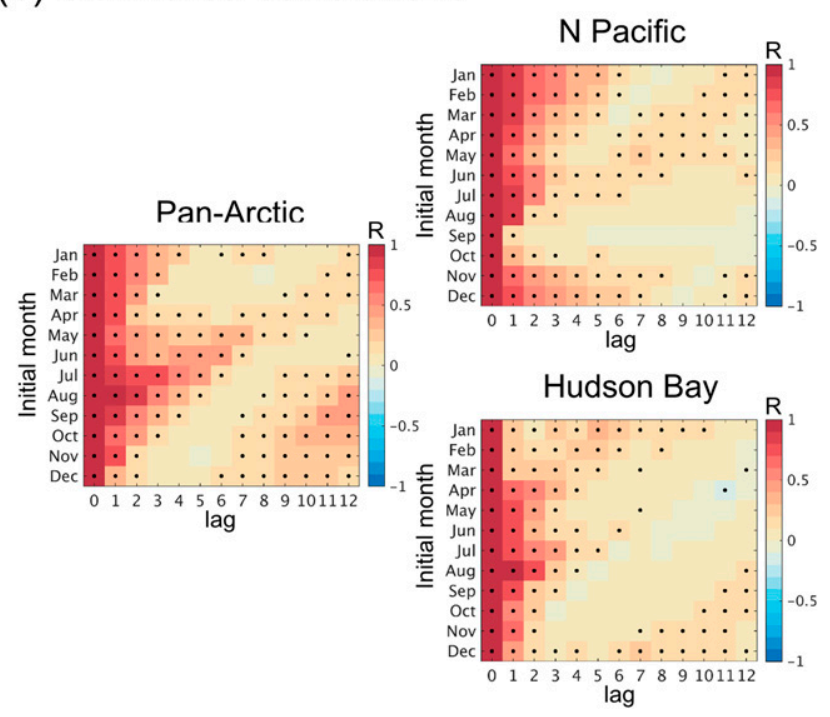


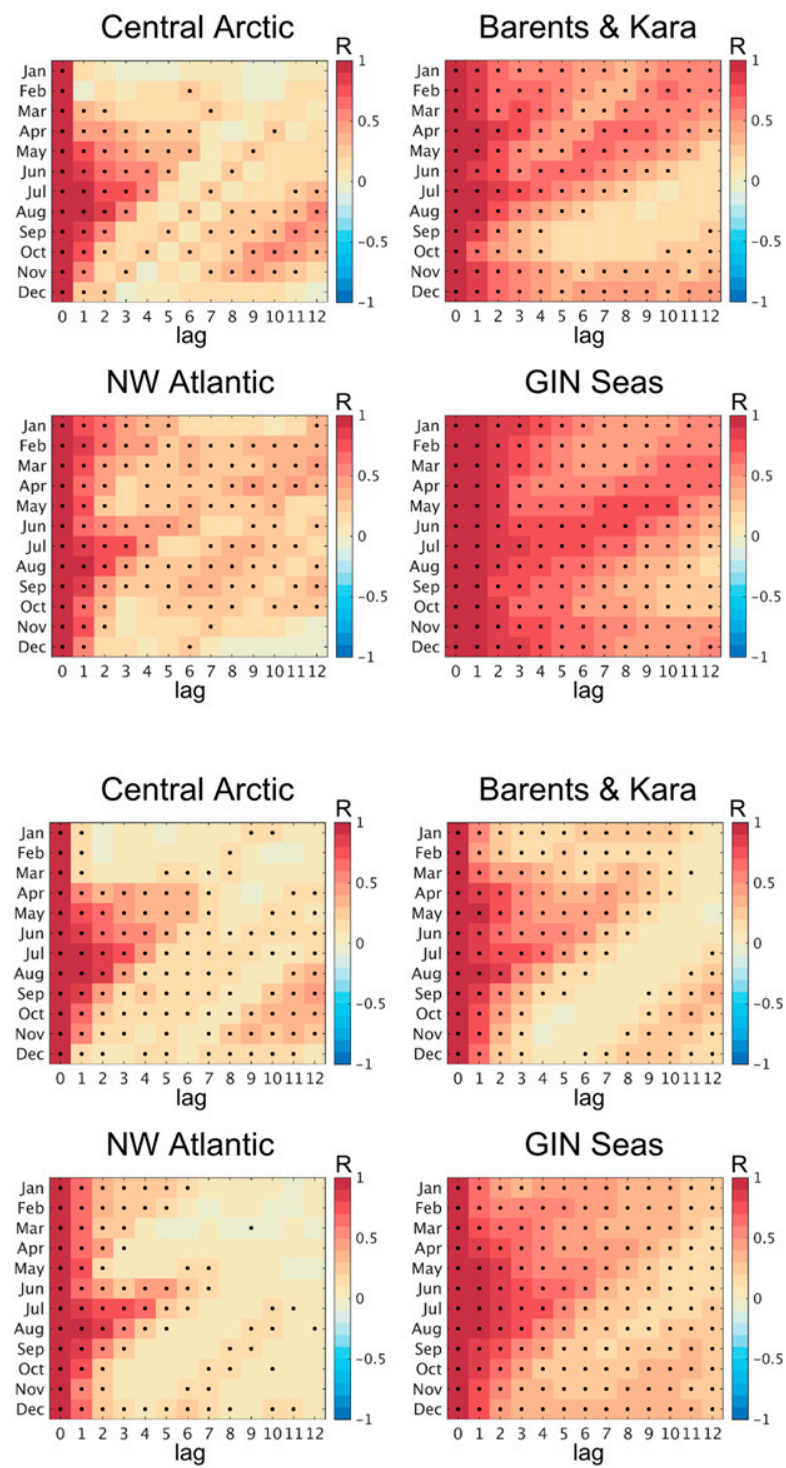

FIG. 4. Lag correlations for monthly area for the (a) pan-Arctic and each Arctic subregion of DYN and (b) pan-Arctic area and area in each Arctic subregion in SOM. Significant correlations are indicated with a black dot.

Arctic regions in Fig. 4. In most regions in the Antarctic, the summer is a major barrier to sea ice area predictability, and then reemergence provides some predictability again beyond summer. The Amundsen-Bellingshausen Seas region is the exception, with high predictability throughout summer. Despite our earlier caution about being wary of excessive multiyear sea ice in some parts of the Antarctic in our simulations, sea ice area predictability in the Southern Ocean is not clearly enhanced by the presence of multiyear ice in a region, particularly over the summer.

Interestingly, we find the regions dominated by strong westward ice motion have the largest predictability on average (e.g., Indian Ocean, Amundsen-Bellingshausen Seas), and regions with significant meridional ice motion have relatively low predictability (e.g., Weddell and Ross Seas). This suggests that prognostic predictability estimated in predictive systems that include advection may be higher than simple estimates of diagnostic predictability like ours. Our analysis does not consider correlation of ice area between different regions, and an analysis that did might find higher predictability for regions such as the Indian Ocean. Another implication is that comprehensive dynamical prediction systems may yield superior results than can be produced from statistical methods that lack a representation of advection. 
(a) DYN area correlations

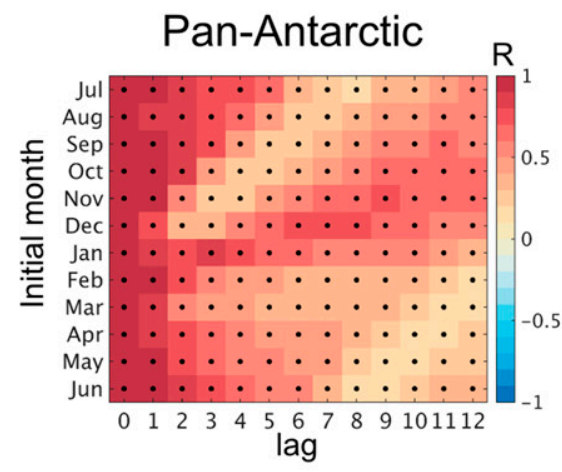

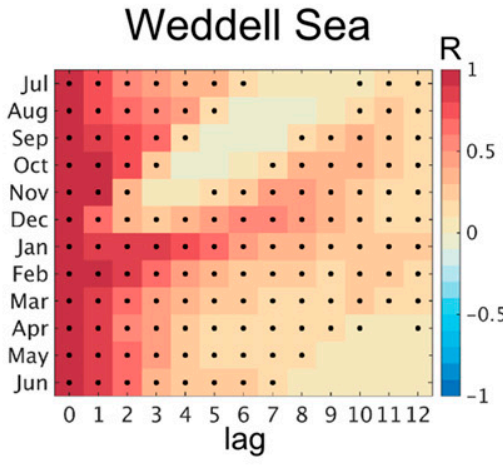

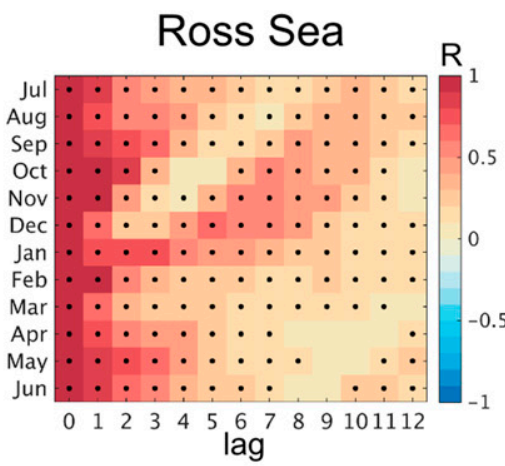

$\begin{array}{llllllll}0 & 1 & 2 & 3 & 4 & 5 & 5 \\ & & & & & \\ \text { lag }\end{array}$

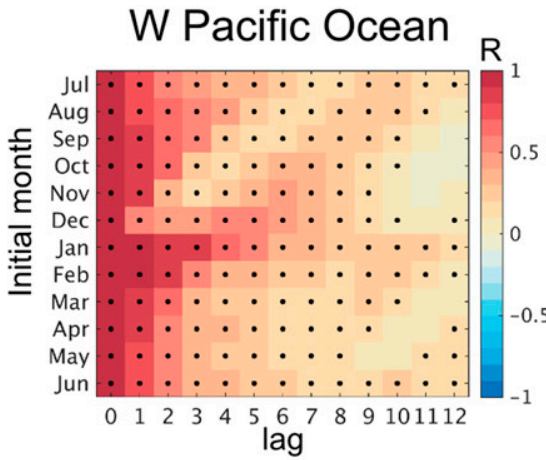

(b) SOM area correlations
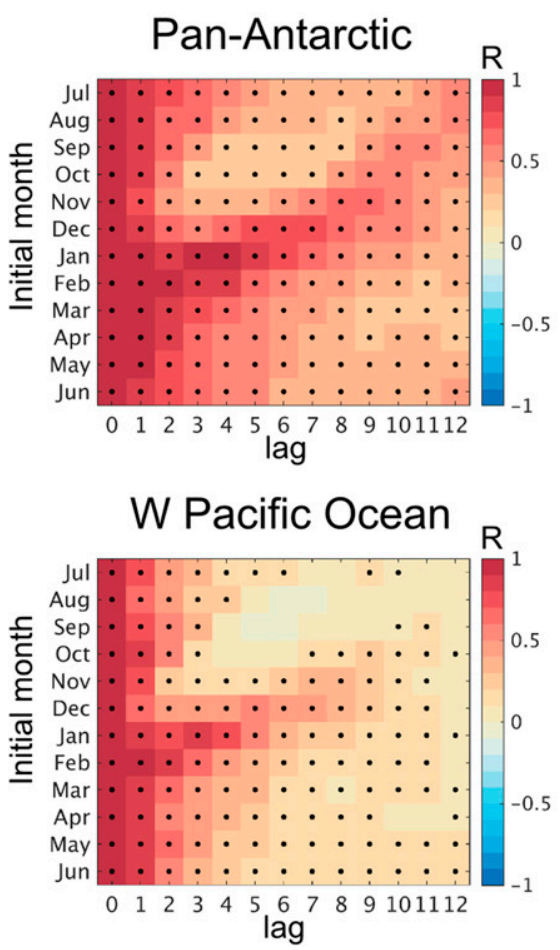
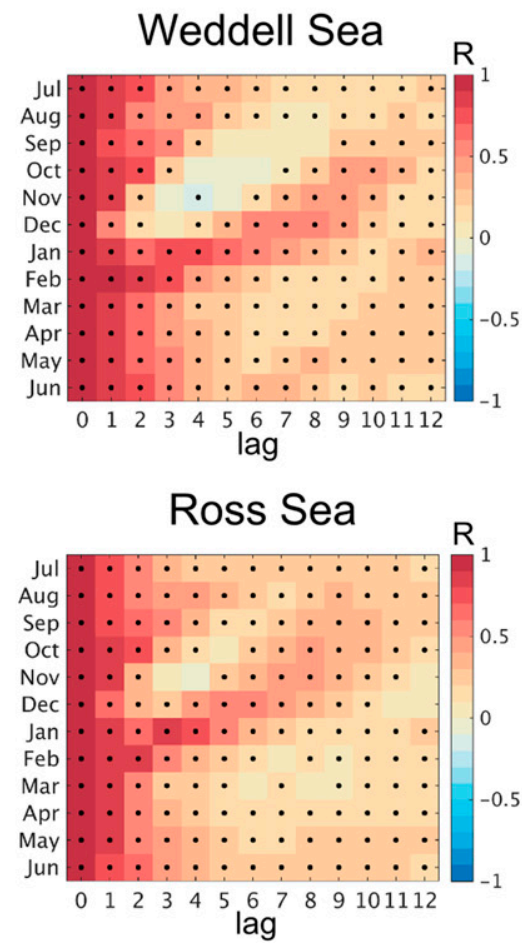

FIG. 5. As in Fig. 4, but for Antarctica.

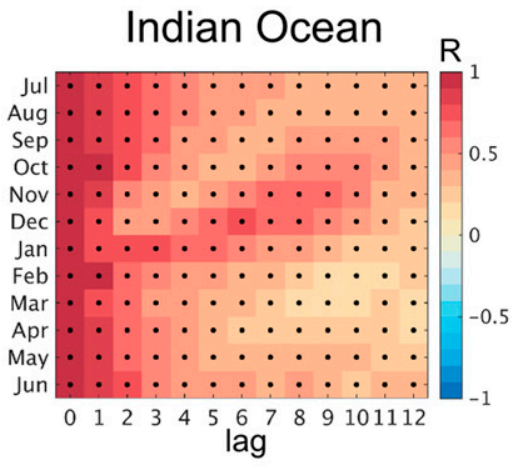

$A B$ Seas

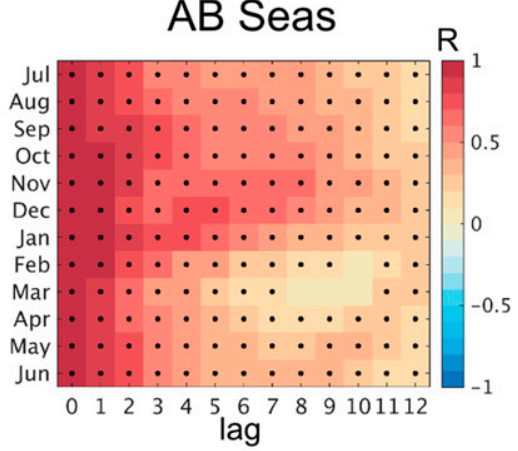

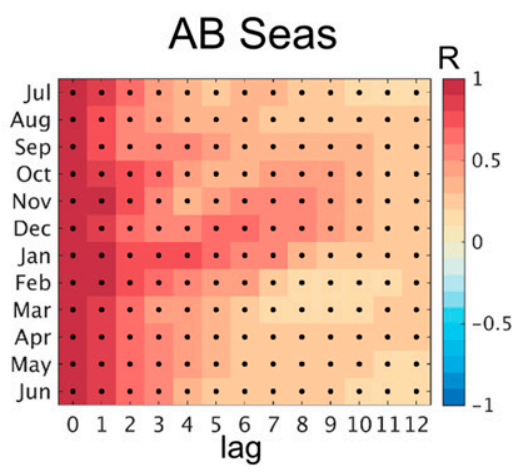


The timing of the SST-linked reemergence is similar among all Antarctic regions and resembles the timing for the pan-Antarctic sea ice area, which is a major change from the highly variable SST reemergence in the Arctic regions. There is weak volume-linked reemergence (i.e., reemergence between melt seasons). In the Weddell Sea and west Pacific, it is seen in late summer sea ice area anomalies that are correlated with the following year's early summer anomalies. In the Indian Ocean and Amundsen-Bellingshausen Seas regions, it occurs in area anomalies between the fall and spring. However, as for the pan-Antarctic, the volume-linked reemergence is much weaker than the SST-linked reemergence in the subregions.

Our description of sea ice area predictability in Antarctic subregions so far relates to either DYN or SOM. However, there are subtle differences in the predictability between the two simulations. At lead times beyond a few months, the correlations with initial months in the winter and spring (upper half of the correlation plots in Fig. 5) in SOM tend to be slightly lower than in DYN. The opposite is true for correlations with initial months in summer and fall (lower half of the plots in Fig. 5). The former is an indication that for SST-linked reemergence, full ocean dynamics (as in DYN) is only slightly more effective at increasing predictability, and only for a fraction of Antarctica, compared to a fixeddepth ocean mixed layer (as in SOM). The latter indicates that although sea ice in DYN is substantially more extensive than in SOM, the influence on volumelinked reemergence is minor. Diminished SST-linked reemergence may be due to advection of SST anomalies around the continent or due to upwelling deep water degrading SST persistence.

\section{d. Predictability of sea ice area looking back in time}

In this section, we reverse the perspective on predictability to find which variables known in advance are the best predictors of sea ice area. The use of long climate model simulations allows us to explore theoretical predictors, some of which are inadequately observed or nonexistent. Chevallier and Salas-Mélia (2012) showed that the area covered by ice thicker than a critical threshold (called thick-ice area) was the best predictor of pan-Arctic September sea ice area for 2-6 months in advance because of the persistence of thick ice through the melt season. We expand on their analysis by quantifying how well this predictor and others correlate with sea ice area in the pan-Arctic and pan-Antarctic and in Pacific and Atlantic sectors of the Arctic. Further, we test three critical thickness thresholds, taken from the thickness boundaries of the multiple-category thickness distribution in CESM. We also consider multiyear ice area as an alternative predictor since it can be observed remotely.

Figures $6 a(1)$ and $6 b(1)$ indicate that in either hemisphere, the total area in late winter is nearly always best predicted by total area in preceding months, and the predictability gap at 4-9-month lead times is striking. In contrast, to predict pan-Arctic area in late summer, like Chevallier and Salas-Mélia (2012), we find that thick-ice area is a good option for lead times of 2 or more months, which fills in an important gap when sea ice area is not a good predictor of itself [see Fig. 6b(2)]. Only at a 2-month lead time is the ice area thicker than $1.39 \mathrm{~m}$ clearly superior to any other predictor, and unlike in Chevallier and Salas-Mélia (2012), the volume is usually just as good a predictor as thick-ice area for lead times of 3 or more months. Roughly the same conclusion can be drawn for the Southern Hemispheric complement (i.e., for predicting the pan-Antarctic sea ice area in late summer), but at lead times greater than 4 months, the predictability from any variable is poor. The only other important distinction is that a critical thickness of $0.64 \mathrm{~m}$ (as compared to $1.39 \mathrm{~m}$ for the Arctic) for the thick-ice area gives the best prediction at a 2-month lead time. We draw the same conclusions about the value of thick-ice area as a predictor from either SOM (not shown) or DYN.

Because multiyear area is currently available for the Arctic from satellite observations, including the Special Sensor Microwave Imager/Sounder (SSM/IS), QuikSCAT, and ASCAT (Kwok 2004; Lindell and Long 2016), we also test this variable as a predictor. It is never of much value to predict total area in late winter in either hemisphere, nor is it worthwhile in late summer in the Antarctic. However, in late summer in the Arctic, multiyear sea ice performs about as well as a predictor of area in Fig. 6a(2) as thick-ice area or volume at lead times of a few months or more.

There are regional variations of predictability in the Arctic that are relevant to local stakeholders. Lag correlations in Fig. 7 were calculated for DYN variables grouped into Atlantic (East Greenland and Barents Seas) and Pacific (Bering, East Siberian, Chukchi, and Beaufort Seas) regions, using the Arctic region mask from the National Snow and Ice Data Center (https://nsidc.org/data/polar-stereo/tools_masks.html\#region_ masks).

Figure $7 \mathrm{a}$ demonstrates large regional differences in March area predictability. Correlations in the Pacific [Fig. 7a(1)] have much in common with the pan-Arctic [Fig. 6a(1)], while those in the Atlantic [Fig. 7b(1)] essentially lack the signature of a predictability gap at 6-10-month lead times that occurs in the Pacific. As in the pan-Arctic, area is nearly always the best predictor of March area in the Atlantic or Pacific. 
(a) Pan-Arctic DYN

(1) Late winter

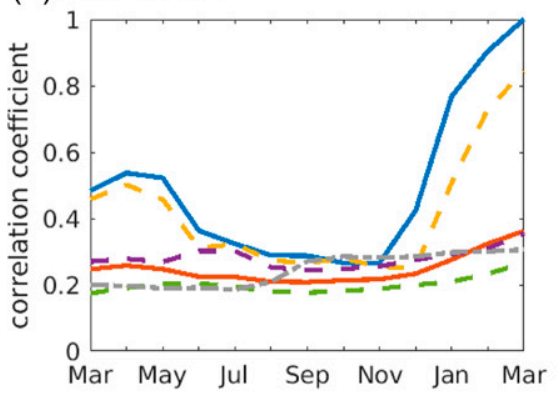

(2) Late summer

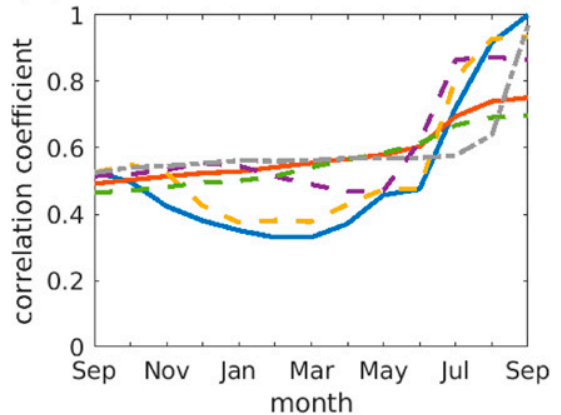

(b) Pan-Antarctic DYN

(1) Late winter

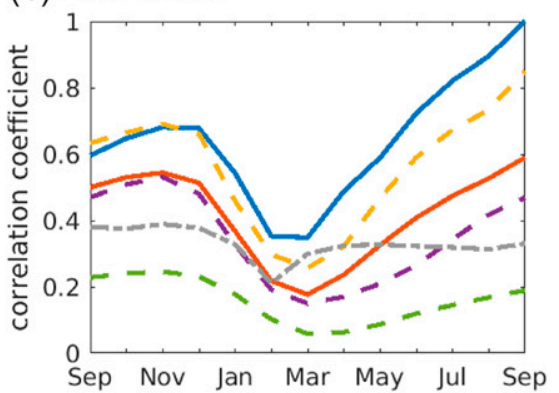

(2) Late summer

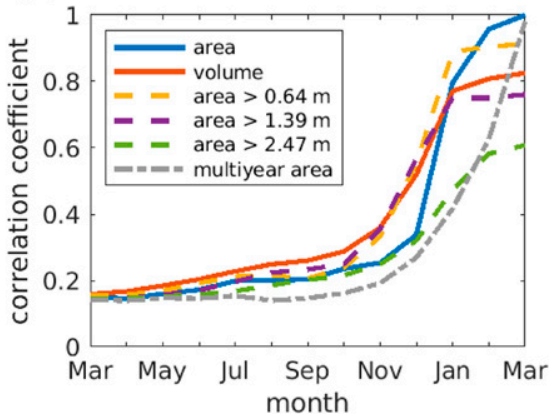

FIG. 6. Lagged correlations of various predictors with the predictand of sea ice area in the (a) pan-Arctic and (b) pan-Antarctic. (top) Correlations for a late winter ice area predictand, which is March in the Arctic and September in the Antarctic. (bottom) Correlations for late summer ice area, which is September in the Arctic and March in the Antarctic. The predictors are area (blue); volume (red); thick-ice area for ice thicker than 0.64 (yellow dashed), 1.39 (purple dashed), and $2.47 \mathrm{~m}$ (green dashed); and multiyear ice area (gray dashed-dotted). All quantities are hemispheric totals.

The predictability of September area in the Atlantic or Pacific (Fig. 7b) is greater than that of the pan-Arctic [Fig. 6a(2)] at 3-9-month lead times, where volume, thick-ice area, and multiyear area fill in as sources of predictability in the months when ice area is a poor predictor, especially in the Pacific.

Differences between the Atlantic and Pacific regions may be due in part to the deeper mixing in the Atlantic region, providing more SST memory [also noted by Bushuk et al. (2017), but for the Labrador Sea]. Further, there is thicker sea ice located near the ice edge and less seasonal advance/retreat of the ice edge in Atlantic-both factors that BlanchardWrigglesworth et al. (2011a) noted contributed to predictability.

The critical thickness is more relevant to later summer predictability in the Pacific sector than the Atlantic sector. In the Pacific, this thickness appears to be around $1.39 \mathrm{~m}$. This thick ice provides the predictability at lead times of 3-9 months. In the Atlantic, there also seems to be some critical thickness between 0.64 and $1.39 \mathrm{~m}$, but the difference in predictability between the two categories is much less than in the Pacific.

\section{Conclusions}

This work highlights commonalities and differences between sea ice area predictability in the Arctic and Antarctic. Lag-correlation analysis was performed on two CESM Large Ensemble preindustrial control simulations, the first with a full-ocean general circulation model and the second with a simple slab ocean. Our results explore predictability from multiple angles: We investigate predictability of both sea ice area and volume, differences in predictability between the poles, the role of ocean dynamics, predictability on a regional scale, and the effectiveness of thick-ice area as a predictor. Our results build on previous modeling and observational studies of the Arctic and the Antarctic and contribute to a growing body of literature comparing predictability in these two regions.

We find predictability of pan-Arctic sea ice area generally falls in line with results from Blanchard-Wrigglesworth 
(a) Late winter DYN

(1) Pacific

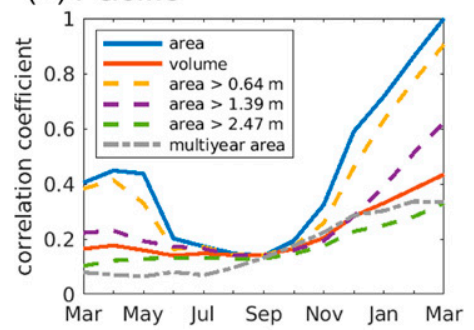

(2) Atlantic

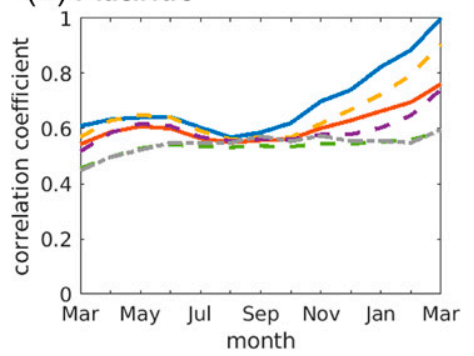

(b) Late summer DYN

(1) Pacific

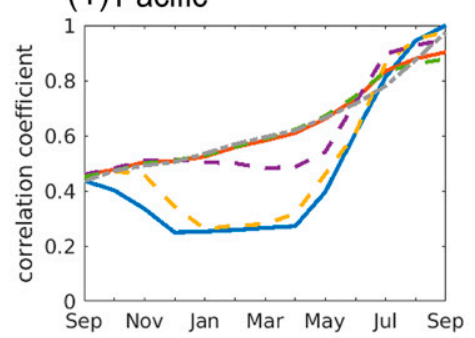

(2) Atlantic

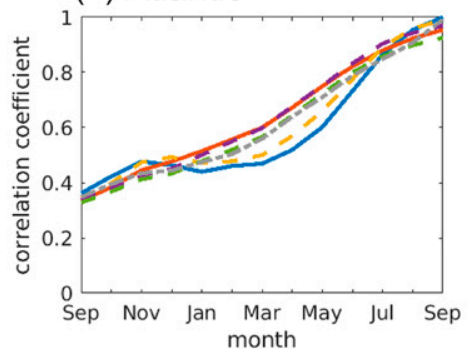

(c) Region map



FIG. 7. Regional Arctic lag correlations for the ice area in the Atlantic and Pacific regions with (a) the March (late winter) sea ice area and (b) the September (late summer) sea ice area. Predictors are as in Fig. 6. (c) A polar view map of the Arctic with the Pacific and Atlantic regions demarcated.

et al. (2011a), Bushuk and Giannakis (2015), and Day et al. (2014). From a forward-looking perspective, where we correlate a given initial monthly anomaly to anomalies in subsequent months, the features of initial persistence and reemergence are present in both hemispheres, though there are differences. The Antarctic winter has the largest persistence of initial area anomalies, giving predictability of ice area extending into spring from area anomalies initialized in early winter. The SST-linked reemergence is similar in the two hemispheres, but there is no volumelinked reemergence in the Antarctic.

Total sea ice volume anomalies are highly persistent in both hemispheres, though more so in the Arctic. In the Antarctic, volume anomalies lose memory rapidly during the melt season. Volume is fairly well correlated with summer area in the pan-Arctic, but only weakly correlated with summer area in the pan-Antarctic. Hence, while total volume may be a helpful predictor of pan-Arctic summer area, it is less useful as a predictor in the Antarctic.

From a backward-looking perspective, there are a number of variables that could offer predictability of the pan-Arctic September area. Just 1 month in advance, August area is the best predictor of September area. From the prior November to July, the best predictors are thickness-related variables-volume, thick-ice area, and multiyear area. Specifically, in June and July, the best predictor is the area thicker than $1.39 \mathrm{~m}$ (ice thickness categories 3-5 in CESM), and from November to May, the best predictor is multiyear ice area. Thicknessrelated variables are not as useful at predicting March area, as expected given that volume and area are decoupled during the winter. For the pan-Antarctic, no variables prior to about October are useful predictors of March area. It is possible that as this century proceeds and the Arctic transitions into a first-year ice regime like that of the Antarctic, late summer in the Arctic will become less predictable as well (see Cheng et al. 2016). Because the model's climate is colder and more stationary than that in recent decades, it would be important to investigate how well each of these predictands performs in a model with modern greenhouse gas forcing. However, because multiyear area appears promising and is available from observations, this work suggests it especially is worth further exploration in predictability studies.

Most research has focused on the role of ocean dynamics on the Arctic (Blanchard-Wrigglesworth et al. 2011a; Bushuk and Giannakis. 2015), but the roles differ between the Arctic and Antarctic. Interactive ocean dynamics increase the persistence of area in both hemispheres. However, there are hemispheric differences in its effect on SST-linked reemergence. In the Arctic, predictability from SST-linked reemergence related to mixed layer processes is substantially better in DYN. In the Antarctic, SST-linked and volume-linked reemergence are generally weaker in DYN, which may be due to ocean and sea ice advection. In either case, this 
points to the importance of including prognostic ocean dynamics and accurate ocean initialization in any climate model used to generate sea ice area forecasts.

Some aspects of regional predictability also differ between the hemispheres. There were many differences year-round in ice area predictability among six regions of the Arctic. Some of the most predictable Arctic regions are also regions that are of economic interest (e.g., Smith and Stephenson 2013). These include the North Pacific, Barents-Kara Seas, and GIN Seas regions. All regions of the Arctic had weaker persistence and reemergence correlations when interactive ocean dynamics were not present. The Antarctic regions were more similar to one another, and their predictability is less affected by the presence or absence of interactive ocean dynamics relative to Arctic regions.

This study analyzed a long period from a pair of model control runs. Arctic climate varies on long time scales (Venegas and Mysak 2000), and the relationships that emerge from a multicentury period may not necessarily hold on a scale of decades or years. Some of the variables we explored, such as thick-ice area, are not presently observable on a large scale, but Massonnet et al. (2015), Kimmritz et al. (2018), and Zhang et al. (2018) have shown that the ice thickness distribution can be successfully constrained with data assimilation in prediction systems with a multiple-category thickness distribution model, such as the sea ice component of CESM. Furthermore, there is room for prognostic predictability work to follow up on this study, particularly in understanding how volume and ocean dynamics affect ice area predictability in CESM.

Acknowledgments. We thank Marika Holland, Daehyun Kim, and Dargan Frierson for helpful discussions and feedback. Comments from three reviewers are greatly appreciated. Computing resources were provided by the Climate Simulation Laboratory at NCAR's Computational and Information Systems Laboratory, sponsored by the National Science Foundation and other agencies. This work was supported by National Science Foundation Graduate Research Fellowship Grant DGE1256082 (ACO) and ONR Grants N00014-15-1-2873 (CMB) and N00014-17-1-2986 (CMB and EBW). The authors declare that they have no conflict of interest. All CESM-LENS output used in this study are available on the Earth System Grid.

\section{REFERENCES}

Alexander, M. A., J. D. Scott, and C. Deser, 2000: Processes that influence sea surface temperature and ocean mixed layer depth variability in a coupled model. J. Geophys. Res., 105, 16 823-16 842, https://doi.org/10.1029/2000JC900074.
Barnhart, K. R., C. R. Miller, I. Overeem, and J. E. Kay, 2016: Mapping the future expansion of Arctic open water. Nat. Climate Change, 6, 280-285, https://doi.org/10.1038/ nclimate2848.

Bitz, C. M., D. S. Battisti, R. E. Moritz, and J. A. Beesley, 1996: Low frequency variability in the Arctic atmosphere, ice, and upper-ocean climate system. J. Climate, 9, 394-408, https:// doi.org/10.1175/1520-0442(1996)009<0394:LFVITA>2.0.CO;2.

Blanchard-Wrigglesworth, E., and C. M. Bitz, 2014: Characteristics of Arctic sea-ice thickness variability in GCMs. J. Climate, 27, 8244-8258, https://doi.org/10.1175/JCLI-D-14-00345.1.

— K. C. Armour, C. M. Bitz, and E. DeWeaver, 2011a: Persistence and inherent predictability of Arctic sea ice in a GCM ensemble and observations. J. Climate, 24, 231-250, https:// doi.org/10.1175/2010JCLI3775.1.

_ C. M. Bitz, and M. M. Holland, 2011b: Influence of initial conditions and climate forcing on predicting Arctic sea ice. Geophys. Res. Lett., 38, L18503, https://doi.org/10.1029/ 2011 GL048807.

Bushuk, M., and D. Giannakis, 2015: Sea-ice reemergence in a model hierarchy. Geophys. Res. Lett., 42, 5337-5345, https:// doi.org/10.1002/2015GL063972.

- — - and A. J. Majda, 2015: Arctic sea ice re-emergence: The role of large-scale oceanic and atmospheric variability. J. Climate, 28, 5477-5509, https://doi.org/10.1175/ JCLI-D-14-00354.1.

- R. Msadek, M. Winton, G. A. Vecchi, R. Gudgel, A. Rosati, and X. Yang, 2017: Skillful regional prediction of Arctic sea ice on seasonal timescales. Geophys. Res. Lett., 44, 4953-4964, https://doi.org/10.1002/2017GL073155.

,,--- G. Vecchi, X. Yang, A. Rosati, and R. Gudgel, 2018: Regional Arctic sea-ice prediction: Potential versus operational seasonal forecast skill. Climate Dyn., https:// doi.org/10.1007/s00382-018-4288-y, in press.

Cavalieri, D. J., and C. L. Parkinson, 2012: Arctic sea ice variability and trends, 1979-2010. Cryosphere, 6, 881-889, https://doi.org/ 10.5194/tc-6-881-2012.

Cheng, W., E. Blanchard-Wrigglesworth, C. M. Bitz, C. Ladd, and P. J. Stabeno, 2016: Diagnostic sea ice predictability in the pan-Arctic and U.S. Arctic regional seas. Geophys. Res. Lett., 43, 11 688-11 696, https://doi.org/10.1002/2016GL070735.

Chevallier, M., and D. Salas-Mélia, 2012: The role of sea ice thickness distribution in the Arctic sea ice potential predictability: A diagnostic approach with a coupled GCM. J. Climate, 25, 30253038, https://doi.org/10.1175/JCLI-D-11-00209.1.

_ and Coauthors, 2017: Intercomparison of the Arctic sea ice cover in global ocean-sea ice reanalyses from the ORA-IP project. Climate Dyn., 49, 1107-1136, https://doi.org/10.1007/ s00382-016-2985-y.

Comiso, J., 2000: Bootstrap sea ice concentrations from Nimbus-7 SMMR and DMSP SSM/I-SSMIS, updated 2015, version 3.1. National Snow and Ice Data Center, accessed 9 September 2018, https://doi.org/10.5067/7Q8HCCWS4I0R.

Day, J. J., S. Tietsche, and E. Hawkins, 2014: Pan-Arctic and regional sea ice predictability: Initialization month dependence. J. Climate, 27, 4371-4390, https://doi.org/10.1175/ JCLI-D-13-00614.1.

Du, H., F. J. Doblas-Reyes, J. García-Serrano, V. Guemas, Y. Souffelt, and B. Wouters, 2012: Sensitivity of decadal predictions to the initial atmospheric and oceanic perturbations. Climate Dyn., 39, 2013-2023, https://doi.org/10.1007/s00382-011-1285-9.

Guemas, V., M. Chevallier, M. Déqué, O. Bellprat, and F. DoblasReyes, 2016: Impact of sea ice initialization on sea ice and 
atmosphere prediction skill on seasonal timescales. Geophys. Res. Lett., 43, 3889-3896, https://doi.org/10.1002/2015GL066626.

Haas, C., and P. Jochmann, 2003: Continuous EM and ULS thickness profiling in support of ice force measurements. Proc. 17th Int. Conf. on Port and Ocean Engineering under Arctic Conditions, Trondheim, Norway, Port and Ocean Engineering under Arctic Conditions, 849-856, http://epic.awi.de/9105/1/ Haa2003c.pdf.

Hawkins, E., S. Tietsche, J. J. Day, N. Melia, K. Haines, and S. Keeley, 2015: Aspects of designing and evaluating seasonal-tointerannual Arctic sea-ice prediction systems. Quart. J. Roy. Meteor. Soc., 142, 672-683, https://doi.org/10.1002/qj.2643.

Holland, M. M., D. A. Bailey, and S. Vavrus, 2011: Inherent sea ice predictability in the rapidly changing Arctic environment of the Community Climate System Model, version 3. Climate Dyn., 36, 1239-1253, https://doi.org/10.1007/s00382-010-0792-4.

- E. Blanchard-Wrigglesworth, J. Kay, and S. Vavrus, 2013: Initial-value predictability of Antarctic sea ice in the Community Climate System Model 3. Geophys. Res. Lett., 40, 2121-2124, https://doi.org/10.1002/grl.50410.

Ivanova, N., O. M. Johannessen, L. T. Pedersen, and R. T. Tonboe, 2014: Retrieval of Arctic sea ice parameters by satellite passive microwave sensors: A comparison of eleven sea ice concentration algorithms. IEEE Trans. Geosci. Remote Sens., 52, 7233-7246, https://doi.org/10.1109/TGRS.2014.2310136.

Jahn, A., J. E. Kay, M. M. Holland, and D. M. Hall, 2016: How predictable is the timing of a summer ice-free Arctic? Geophys. Res. Lett., 43, 9113-9120, https://doi.org/10.1002/2016GL070067.

Johnson, C. M., P. Lemke, and T. P. Barnett, 1985: Linear prediction of sea ice anomalies. J. Geophys. Res., 90, 5665-5675, https://doi.org/10.1029/JD090iD03p05665.

Kay, J. E., and Coauthors, 2015: The Community Earth System Model (CESM) Large Ensemble Project: A community resource for studying climate change in the presence of internal climate variability. Bull. Amer. Meteor. Soc., 96, 1333-1349, https://doi.org/10.1175/BAMS-D-13-00255.1.

Kimmritz, M., F. Counillon, C. M. Bitz, F. Massonnet, I. Bethke, and Y. Gao, 2018: Optimising assimilation of sea ice concentration in an Earth system model with a multicategory sea ice model. Tellus, 70A, 1435945, https://doi.org/10.1080/ 16000870.2018.1435945.

Kwok, R., 2004: Annual cycles of multiyear sea ice coverage of the Arctic Ocean: 1999-2003. J. Geophys. Res., 109, C11004, https://doi.org/10.1029/2003JC002238.

Lamers, M., A. Pristupa, B. Amelung, and M. Knol, 2016: The changing role of environmental information in Arctic marine governance. Curr. Opin. Environ. Sustainability, 18, 49-55, https://doi.org/10.1016/j.cosust.2015.08.015.

Lemke, P., E. W. Trinkl, and K. Hasselmann, 1980: Stochastic dynamic analysis of polar sea ice variability. J. Phys. Oceanogr., 10, 2100-2120, https://doi.org/10.1175/1520-0485(1980)010<2100: SDAOPS $>2.0 . \mathrm{CO} ; 2$.
Lindell, D. B., and D. G. Long, 2016: Multiyear Arctic ice classification using ASCAT and SSMIS. Remote Sens., 8, 294, https://doi.org/10.3390/rs8040294.

Massonnet, F., T. Fichefet, and H. Goosse, 2015: Prospects for improved seasonal Arctic sea ice predictions from multivariate data assimilation. Ocean Modell., 88, 16-25, https://doi.org/ 10.1016/j.ocemod.2014.12.013.

Meehl, G. A., and Coauthors, 2013: Climate change projections in CESM1(CAM5) compared to CCSM4. J. Climate, 26, 62876308, https://doi.org/10.1175/JCLI-D-12-00572.1.

Meier, W. N., F. Fetterer, J. S. Stewart, and S. Helfrich, 2015: How do sea ice concentrations from operational data compare with passive microwave estimates? Implications for improved model evaluations and forecasting. Ann. Glaciol., 56, 332-340, https://doi.org/10.3189/2015AoG69A694.

Msadek, R., G. A. Vecchi, M. Winton, and R. G. Gudgel, 2014: Importance of initial conditions in seasonal predictions of Arctic sea ice extent. Geophys. Res. Lett., 41, 5208-5215, https://doi.org/10.1002/2014GL060799.

Parkinson, C. L., and D. J. Cavalieri, 2012: Antarctic sea ice variability and trends, 1979-2010. Cryosphere, 6, 871-880, https:// doi.org/10.5194/tc-6-871-2012.

Shu, Q., Z. Song, and F. Qiao, 2015: Assessment of sea ice simulations in the CMIP5 models. Cryosphere, 9, 399-409, https:// doi.org/10.5194/tc-9-399-2015.

Sigmond, M., J. C. Fyfe, G. M. Flato, V. V. Kharin, and W. J. Merryfield, 2013: Seasonal forecast skill of Arctic sea ice area in a dynamical forecast system. Geophys. Res. Lett., 40, 529534, https://doi.org/10.1002/grl.50129.

Smith, L. C., and S. R. Stephenson, 2013: New trans-Arctic shipping routes navigable by midcentury. Proc. Natl. Acad. Sci. USA, 110, 4871-4872, https://doi.org/10.1073/pnas.1214212110.

Venegas, S. A., and L. A. Mysak, 2000: Is there a dominant timescale of natural climate variability in the Arctic? J. Climate, $\mathbf{1 3}$ 3412-3434, https://doi.org/10.1175/1520-0442(2000)013<3412: ITADTO $>2.0 . \mathrm{CO} ; 2$.

Yang, C.-Y., J. Liu, Y. Hu, R. M. Horton, L. Chen, and X. Cheng, 2016: Assessment of Arctic and Antarctic sea ice predictability in CMIP5 decadal hindcasts. Cryosphere, 10, 2429-2452, https:// doi.org/10.5194/tc-10-2429-2016.

Zhang, R., 2015: Mechanisms for low-frequency variability of summer Arctic sea ice extent. Proc. Natl. Acad. Sci. USA, 112, 4570-4575, https://doi.org/10.1073/pnas.1422296112.

Zhang, Y.-F., C. M. Bitz, J. L. Anderson, N. Collins, J. Hendricks, T. Hoar, K. Raeder, and F. Massonnet, 2018: Insights on Sea Ice Data Assimilation 1 from perfect model observing system simulation experiments. J. Climate, 31, 5911-5926, https:// doi.org/10.1175/JCLI-D-17-0904.1.

Zunz, V., H. Goosse, and S. Dubinkina, 2015: Impact of the initialisation on the predictability of the Southern Ocean sea ice at interannual to multi-decadal timescales. Climate Dyn., 44, 2267-2286, https://doi.org/10.1007/s00382-014-2344-9. 